accustomed to regulation, has adopted company-wide solutions, and the US Food and Drug Administration has determined that the use of electronic notebooks is acceptable in drug filings. This high degree of usage is in stark contrast to academia.

So why bother? Most importantly, e-notebooks allow the sharing of data, to the immediate benefit of collaborators (for examples, see Nature 436, 20; 2005). And just knowing that a notebook is available to others in the lab, and archived for the future, should compel the keeping of better records.

But one can and should go further. Electronic notebooks can be archived by researchers' employers, with a number of attendant benefits. If each notebook (or subset of it) is allocated a unique identifying code - a permanent alphanumeric string containing information about provenance, creation dates and digital location - it can be cited in journals as a confirmation that the data are safely stored, ultimately available and sharable (with due regard for the rights of the researchers involved). It also confirms that the original data can be retrieved in the case of errors or accusations of fraud. No longer would claims of lost notebooks be brought up in misconduct investigations.

An additional benefit is that the data may have a value not only to

\section{Hard to defend}

\section{US missile defence plans require scrutiny.}

T he utility and value of missile defence systems remain unproven, but the United States plans to go ahead and deploy one in Eastern Europe regardless. The plan has delighted some former satellites of the Soviet Union, such as Poland, but irked other European nations, and remains of questionable relevance to US defence needs. Unfortunately, no one in Congress is saying so.

Defence officials say that ten interceptors in Poland and a radar in the Czech Republic are needed to protect the United States and its allies from yet-to-be developed Iranian ballistic missiles. But Russia's President Vladimir Putin believes that the shield has other purposes. On 27 April, shortly after a visit from US defence secretary Robert Gates, Putin announced that he would retaliate against the missile defence plan by pulling out of the 1990 Treaty on Conventional Armed Forces in Europe. US allies in Western Europe are irritated, meanwhile, that negotiations over the expansion will take place through bilateral channels, circumventing NATO.

But Democrats in Congress, who have long been suspicious of the missile defence system, are reluctant to oppose it. At Senate hearings last week, the Missile Defense Agency asked for nearly $\$ 9$ billion in the next financial year, most of it to purchase early-warning radars and long-range interceptors, including some of the equipment for the European sites.

The panel's chairman, Daniel Inouye (Democrat, Hawaii), told the agency's leaders that they should be "proud" of their achievements and called for a beefing up of the system's capability. Two of the system's opponents, Dianne Feinstein (Democrat, California) and Byron Dorgan (Democrat, North Dakota), did raise specific concerns about its ability to detect decoys. But nobody was ready to side the researchers who produced them but to others too, independently of the publications that report them. That value can be recognized explicitly by citation of the identifying code, enabling due credit to be given to the researchers who produced them.

Any change that requires adjustments to the way scientists go about their daily work meets with resistance and, for many researchers, lab notebooks are wrongly considered to be private property. Academic acceptance of e-notebooks will not improve unless universities promote their use and recognize that e-notebooks can help them fulfil their responsibilities as the owners of most grant-funded data. There will be challenges with respect to maintenance of the archives and the standardization of software, but those who have invested in this approach have seen the benefits.

Institutions therefore need to show leadership in this area, and funding agencies should provide additional infrastructure support earmarked for the development and upkeep of electronic notebook systems. Funding agencies also need to recognize that, by providing such support, some of the concerns over the loss of data can be assuaged, and the rigour and transparency of publicly funded research will be improved.

with Putin and publicly question the agency's plans to field the new interceptors.

That's unfortunate, because the missile defence project remains as technically questionable and strategically undesirable as ever. In tests, the interceptors have had mixed success at striking incoming warheads. Physicists have long been cautious about their effectiveness, and advocacy groups such as the Union of Concerned Scientists and the Federation of American Scientists continue to express deep scepticism over whether such a system can ever stop an incoming ballistic-missile attack. They think the system remains vulnerable to decoys and other relatively simple countermeasures.

Furthermore, this brittle defence can do nothing to stop cruise missiles of the sort already developed by Iran, nor can it intercept a warhead smuggled into the country on a truck or boat. In today's security environment, these threats are more direct than the longrange missile capability that Iran and North Korea do not yet have.

But last week's hearing suggests that missile defence may have become a pariah issue for the Democrats. Like gun control - an idea that cannot speak its name, even in the wake of last month's horrific shooting at Virginia Tech - the abandonment of missile defence seems to be politically out-of-bounds. Most leading Democrats are reluctant to oppose the programme - a form of defence that some polls suggest Americans mistakenly think they already have - in case it makes them look soft on national security. Nobody wins elections by dispelling illusions of security, and a few billion dollars is a small price to pay for political expediency, at least where Pentagon budgets are concerned.

But if the system is sham, as well as a menace to foreign relations, no more money should be wasted on it. Instead of humbly waving the programme's massive budget through, Congress should be asking the Government Accountability Office to establish exactly what US taxpayers have got for the tens of billions of dollars that the Bush administration has expended in pursuit of this myopic vision. 